\title{
Development and Validation of a Novel Stability Indicating RP-UPLC Method for Simultaneous Estimation of Methylparaben, Mometasone Furoate and Eberconazole Nitrate in Combined Topical Pharmaceutical Dosage Form
}

\author{
CHINMOY ROY ${ }^{1,2^{*}}$ and JITAMANYU CHAKRABARTY ${ }^{2}$ \\ ${ }^{1}$ Analytical Research and Development, Integrated Product Development, Dr. Reddy's \\ Laboratories Ltd.,Bachupally, Hyderabad-500090, Andhra Pradesh, India. \\ ${ }^{2}$ Department of Chemistry, National Institute of Technology, \\ Durgapur-713209, West Bengal, India \\ chinmoyanalyst@gmail.com
}

Received 6 June 2013 / Accepted 10 July 2013

\begin{abstract}
A novel, rapid, simple, stability indicating RP-UPLC method development and validation for simultaneous estimation of methylparaben (MP), mometasone furoate (MF) and eberconazole nitrate $(\mathrm{EN})$ in topical pharmaceutical dosage form. Isocratic chromatographic separation was achieved on Acquity BEH C18, column using mobile phase consist of buffer $(0.1 \% \mathrm{v} / \mathrm{v}$ triethylamine in water $\mathrm{pH} 6.0$ by Glacial acetic acid), acetonitrile in the ratio $(40: 60, \mathrm{v} / \mathrm{v})$ at flow rate $0.4 \mathrm{~mL} / \mathrm{min}$ and detection was monitored at $235 \mathrm{~nm}$ by using photo-diode array detector. The method shows excellent linearity over the range of $2.75-152.7 \mu \mathrm{g} / \mathrm{mL}, 4.45-60.7 \mu \mathrm{g} / \mathrm{mL}$ and $9.10-606.6 \mu \mathrm{g} / \mathrm{mL}$ for methylparaben, mometasone furoate and eberconazole nitrate respectively. Recovery was found for all the components to be in the range of $98.4-101.7 \%$. Stability indicating capability of developed method was established by analysing forced degradation samples in which spectral purity of methylparaben, mometasone furoate and eberconazole nitrate along with separation of degradation products from analytes peak. The proposed method was successfully applied for the quantitative estimation of MP, MF and EN in cream sample.
\end{abstract}

Keywords: RP-UPLC, Forced degradtion, Mometasone furoate, Eberconazole nitrate, Topical dosage form

\section{Introduction}

Eberconazole nitrate (EN), topical antimycotic agent chemically known as: 1-(2, 4-dichloro10,11-dihydro-5H-dibenzo[a,d]cyclohepten-5-yl)- $1 H$-imidazole nitrate used topically in the treatment of superficial fungal infections. It is a basic, white, amorphous powder ${ }^{1,4}$.

Mometasone furoate (MF), topical corticosteroid chemical known as: $(11 \beta, 16 \alpha)-9,21$ dichloro-11-hydroxy-16- methyl-3, 20-dioxopregna-1, 4-dien-17-yl 2-furoate; has antiinflammatory, anti-pruritic and vasoconstrictive properties. Mometasone reduces the action of allergic reactions, eczema and psoriasis that causes inflammation, redness and swelling. 
For the treatment of mild to moderate inflammed cutaneous mycoses with antimycotic activity combination of eberconazole nitrate and mometasone furoate used. The preservative system is an important part of semi solid formulations in preventing the deterioration of formulations from microbial contamination. Methylparaben and its salts are the most commonly used preservatives and have been used for many years ${ }^{5-7}$.

A detailed literature survey for methylparaben, mometasone furoate and eberconazole nitrate revealed that determination of individual compound or combination with other drugs have been reported by $\mathrm{HPLC}^{2-16}, \mathrm{LCMS}^{17-18}$, electrophoresis ${ }^{19}$ and spectrophotometric method $^{20}$.

To the best of our knowledge, no RP-UPLC stability indicating method has been reported for the rapid simultaneous determination of MP, MF and EN in combined topical pharmaceutical formulation. Therefore, it is necessary to develop a new rapid and stabilityindicating method for simultaneous estimation of three compounds (MP, MF and EN) in topical pharmaceutical formulation. The proposed method is able to separates MP, MF and EN with each other and from other degradation products. Thereafter, this method was validated according to the ICH guideline ${ }^{21}$ and successfully applied for separation and quantification of all compounds of interest in the topical pharmaceutical formulation. Chemical structures of all compounds are presented in Figure 1.

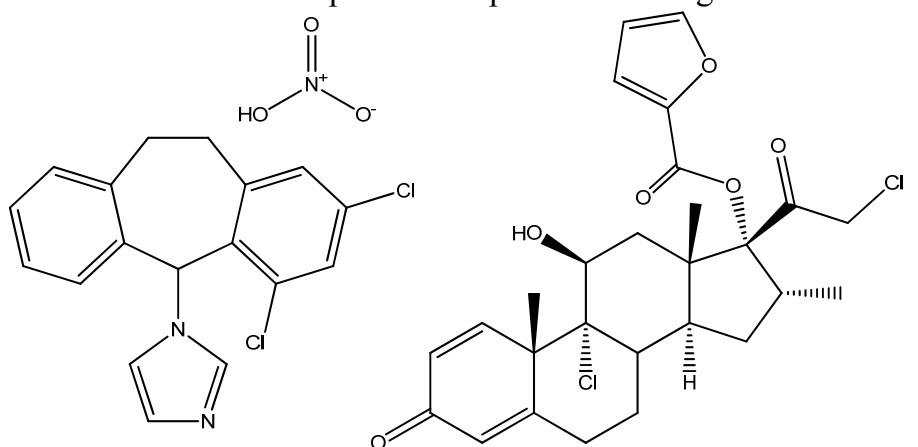

(a) (b)<smiles>COC(=O)c1ccc(O)cc1</smiles>

(c)

Figure 1. Chemical structure of (a) Eberconazole nitrate (b) Mometasone furoate (c) Methylparaben

\section{Experimental}

Drug product, Placebo matrix, working standards were provided by Dr. Reddys Lab, India. HPLC grade acetonitrile, triethylamine and glacial acetic acid were used of Rankem, India. $0.22 \mu \mathrm{m}$ nylon membrane filter, $0.22 \mu \mathrm{m}$ PVDF syringe filter and $0.22 \mu \mathrm{m}$ nylon syringe filter was used of Millipore, India. Water for HPLC was generated using Milli-Q Plus water purification system (Millipore, Milford, MA, USA), analytical grade hydrochloric acid, sodium hydroxide pellets and $30 \%(\mathrm{v} / \mathrm{v})$ hydrogen peroxide solution were obtained from Rankem, India.

\section{Chromatographic parameters and equipments}

All chromatographic experiments were performed on waters acquity UPLC system (Waters, Empower2 software, USA) in the isocratic mode. Separation was achieved on accquity BEH C18 $(100 \times 2.1 \mathrm{~mm}, 1.7 \mu)$ column as stationary phase by using mixture of buffer (buffer $=0.1 \% \mathrm{v} / \mathrm{v}$ triethylamine in water $\mathrm{pH} 6.0$ by glacial acetic acid) : acetonitrile $(40: 60, \% \mathrm{v} / \mathrm{v})$ 
as mobile phase and isocratic mode. Other parameters such as run time 4.0 minutes, $0.4 \mathrm{~mL} / \mathrm{min}$ as flow rate, injection volume of $1 \mu \mathrm{L}$, column temperature of $40{ }^{\circ} \mathrm{C}$ were finalized during development. MF, EN and MP was detected at $235 \mathrm{~nm}$. Acetonitrile was used as diluents. The stress degraded samples and the solution stability samples were analyzed using a PDA detector covering the range of 200-400 nm. Photo-stability chamber (Sanyo, Leicestershire, UK) used for photolytic light stressed sample. Dry air oven (Cintex, Mumbai, India). Cintex digital water bath was used for specificity study.

\section{Procedure}

\section{Standard solution preparation}

The stock solutions of methylparaben $(1000 \mu \mathrm{g} / \mathrm{mL})$, mometasone furoate $(400 \mu \mathrm{g} / \mathrm{mL})$ and eberconazole nitrate $(4000 \mu \mathrm{g} / \mathrm{mL})$ were prepared by dissolving an appropriate amount of standard substances in acetonitrile, separately. Working standard solution was prepared by mixing above stock solutions of methylparaben, mometasone furoate and eberconazole nitrate with final concentration of $100 \mu \mathrm{g} / \mathrm{mL}, 40 \mu \mathrm{g} / \mathrm{mL}$ and $400 \mu \mathrm{g} / \mathrm{mL}$ respectively.

\section{Cream sample preparation}

An accurately weighed $1 \mathrm{~g}$ of sample (equivalent to $20 \mathrm{mg}$ of EN, $2 \mathrm{mg}$ of MF) was taken into $50 \mathrm{~mL}$ volumetric flask. About $35 \mathrm{~mL}$ of acetonitrile was added to this volumetric flask and sonicated in an ultrasonic bath for $15 \mathrm{~min}$ with intermittent shaking, diluted to the volume with acetonitrile, mixed well. Filtered a portion of solution through $0.22 \mu \mathrm{m}$ nylon syringe filter and the filtrate was collected after discarding first few milliliters.

\section{Placebo (other substances without MP, MF and EN) solution preparation}

An accurately weighed $1 \mathrm{~g}$ of placebo sample was taken into $50 \mathrm{~mL}$ volumetric flask. About $35 \mathrm{~mL}$ of acetonitrile was added to this volumetric flask and sonicated in an ultrasonic bath for $15 \mathrm{~min}$ with intermittent shaking, diluted to the volume with acetonitrile, mixed well. Filtered a portion of solution through $0.22 \mu \mathrm{m}$ nylon syringe filter and the filtrate was collected after discarding first few milliliters.

\section{Procedure for method validation}

The method was validated for linearity, precision, accuracy solution stability, filter compatibility, limit of detection (LOD), limit of quantification (LOQ), specificity-forced degradation studies and robustness.

\section{System suitability}

To ensure that UPLC testing system was suitable for the intended application, the system suitability was assessed by five replicate analysis of system suitability solution and chromatographic parameters were evaluated. The acceptance criteria were not more than $2.0 \%$ for the RSD of the peak areas and tailing factor of the analyte peaks. The acceptance criteria were not less than 3000,5000 and 7500 for the plate count of the MP, MF and EN peak respectively.

\section{Specificity-forced degradation studies}

The forced degradation studies were executed to demonstrate whether the analytical method were stability-indicating and could unequivocally assess the analyte in presence of impurities and degradation products. Combined cream of MP, MF and EN were stressed under thermolytic, photolytic, acid hydrolytic, base hydrolytic and oxidative stress conditions 
to result expect $0-50 \%$ partial degradation of the drugs. All stress decomposition studies were performed at an initial drug concentration of 100,40 and $400 \mu \mathrm{g} / \mathrm{mL}$ for MP, MF and EN respectively.

\section{Acid degradation sample}

For acid hydrolysis, solution was prepared by dispersing and dissolving cream sample into $15 \mathrm{~mL}$ of acetonitrile. Acid hydrolysis was performed by adding $2 \mathrm{~mL}$ of $1 \mathrm{~N} \mathrm{HCl}$ and mixture was kept at room temperature for 30 minutes. Neutralized the solution with $2 \mathrm{~mL}$ of $1 \mathrm{~N} \mathrm{NaOH}$ solution and further procced as per sample preparation.

\section{Base degradation sample}

For acid hydrolysis, solution was prepared by dispersing and dissolving cream sample into $15 \mathrm{~mL}$ of acetonitrile. Base hydrolysis was performed by adding $1 \mathrm{~mL}$ of $0.5 \mathrm{~N} \mathrm{NaOH}$ and mixture was kept at room temperature for 15 minutes. Neutralized the solution with $1 \mathrm{~mL}$ of $0.5 \mathrm{~N} \mathrm{HCl}$ solution and further procced as per sample preparation.

\section{Peroxide oxidation sample}

For oxidation study, solution was prepared by dispersing and dissolving cream sample into $15 \mathrm{~mL}$ of acetonitrile. Oxidative study was performed by adding $1 \mathrm{~mL}$ of $10 \% \mathrm{v} / \mathrm{v}$ hydrogen peroxide $\left(\mathrm{H}_{2} \mathrm{O}_{2}\right)$ and mixture was kept at room temperature for 30 minutes. Further procced as per sample preparation.

\section{Thermal exposed sample}

For thermal stress testing, the cream sample was placed in convection oven and exposed to heat at $75^{\circ} \mathrm{C}$ for $6 \mathrm{~h}$.

\section{Photolytic light exposed sample}

For photo stress testing, the cream sample was placed in photolytic chamber to expose in UV and visisble light (1.2 million lux hours and $200 \mathrm{wh} / \mathrm{m}^{2}$ ).

\section{Precision}

The precision of the developed method was assessed by performing repeatability and intermediate precision (inter-day) at an initial drug concentration of 100,40 and $400 \mu \mathrm{g} \mathrm{mL}^{-1}$ for MP, MF and EN respectively, in one day and \% RSD was calculated to determine repeatability precision. These studies were also repeated on different days to determine intermediate precision.

\section{Accuracy}

To confirm the methods accuracy, recovery experiments were checked by standard addition method. The recovery experiments were performed in triplicate at 50, 100 and $150 \%$ concentration levels of the amount of the analytes in in-house mixture of cream excipients (placebo).

\section{Limit of detection and limit of quantification}

The limit of detection (LOD) and limit of quantification (LOQ) were defined as the lowest concentration of analyte in a sample that can be detected and quantified. The standard solutions of MP, MF and EN for LOD and LOQ were prepared by diluting them in acetonitrile sequentially. The LOD and LOQ were determined by signal to noise $(\mathrm{S} / \mathrm{N})$ ratio for each compound through analyzing a series of diluted solutions until the $\mathrm{S} / \mathrm{N}$ ratio yield 3 for LOD and 10 for LOQ, respectively. 


\section{Linearity}

Six levels of calibration standard solutions were prepared from the stock solutions at concentration from 2.75-152.7 $\mu \mathrm{g} / \mathrm{mL}$ for MP, 4.45-60.7 $\mu \mathrm{g} / \mathrm{mL}$ for MF and 9.10-606.6 $\mu \mathrm{g} / \mathrm{mL}$ for EN to encomposed the expected concentration in measured samples. Calibration curves were constructed by plotting areas versus concentrations of MP, MF and EN and then subjected to treat by least-squeres linear regression analysis.

\section{Robustness}

To determine the robustness of the method the experimental conditions were deliberately changed. The flow rate of the mobile phase $(0.4 \pm 0.04 \mathrm{~mL} / \mathrm{min})$, column oven temperature $\left(40 \pm 5{ }^{\circ} \mathrm{C}\right)$, mobile phase buffer $\mathrm{pH}(6.0 \pm 0.2)$, varying in acetonitrile composition $(60 \pm 10 \%)$. In each case, the \% RSD values were calculated for the obtained peak area. The number of theoretical plates and tailing factors were compared with those obtained under the optimized conditions.

\section{Solution stability}

In order to demonstrate the stability of sample solutions, the solution was tested at intervals of $0,12,24 \mathrm{~h}$ by storage it at ambient temperature for $24 \mathrm{~h}$. The stability of solutions was appreciated by comparing assay results of peak area MP, MF and EN.

\section{Filter compatibility}

Filter compatibility was performed for nylon $0.22 \mu \mathrm{m}$ syringe filter (Millipore) and PVDF $0.22 \mu \mathrm{m}$ syringe filter (Millipore). To confirm the filter compatibility in proposed method, filtration recovery experiment was carried out by sample filtration technique. Sample was filtered through both syringe filter and percentage assay was determined and compared against centrifuged sample.

\section{Results and Discussion}

\section{Method development and optimization}

The primary target in developing UPLC method is to achieve simultaneous determination of $\mathrm{MP}, \mathrm{MF}$ and EN in topical formulations under common chromatographic conditions; those are applicable to routine quality control of products in pharmaceutical and cosmetic industries.

\section{Mobile phase and chromatographic conditions optimization}

Column selection and mobile phase selection were done simultaneously. A method development was started with HSS C18 $(100 \times 2.1 \mathrm{~mm}, 1.7 \mu \mathrm{m})$ column as stationary phase. mobile phase was buffer $(0.1 \%$ triethyl amine $\mathrm{pH} 6.0$ with glacial acetic acid $)$ : methanol, $20: 80 \mathrm{v} / \mathrm{v}$. Flow rate $0.4 \mathrm{~mL} / \mathrm{min}$, column temperature $40{ }^{\circ} \mathrm{C}$. Late elution of EN peak was observed. Further trial was taken by replacing methanol with acetonitrile from mobile phase component and found that the peak shape of EN was not symmetrical (1.5 peak tailing observed). Different mobile phase buffer $\mathrm{pH}$ (ranging from 2.5 to 6.5) were employed with phosphate, acetate, perchlorate and formic acid buffers to reduce the peak tailings, but the buffer $\mathrm{pH}$ did not play any role in peak tailing for EN. Then trial was taken with different column BEH C18 $(100 \times 2.1 \mathrm{~mm}, 1.7 \mu \mathrm{m})$ keeping mobile phase buffer $(0.1 \%$ triethyl amine pH 6.0 with glacial acetic acid) : Acetonitrile, $20: 80 \mathrm{v} / \mathrm{v}$ while flow rate was $0.4 \mathrm{~mL} / \mathrm{min}$, column temperature $40^{\circ} \mathrm{C}$ and found that the peak shape of EN was symmetrical (1.2 peak tailing observed). when base degradation sample was injected into the same chromatographic 
conditions co-elution of base degradant peak with MF peak was observed. Different organic phase ratio (ranging from $20 \%$ to $80 \%$ ) in mobile phase component employed to separate base degradant peak from MF peak of base degradation sample. From the above experiments, it was observed that to separate base degradant peak from MF peak in base degradation sample organic phase ratio played a role. Good peak shaped for all components with well resolved degradant peaks were observed in all stressed condition samples.

Acetonitrile was used as diluent by considering solubility of all components wavelength was selected by injecting known concentration of each of MP, MF and EN into UPLC with PDA detector and evaluated for UV spectra of each of component. A common wavelength for the simultaneous determination of all components was selected as $235 \mathrm{~nm}$ by overlaying spectra and wavelength at which all components have significant absorbance.

Extraction of active components from semisolid sample matrix with acceptable recovery is very critical aspect for sample preparation and was achieved by choose of right diluent in following manner. Considering solubility of all components, Acetonitrile was used as diluent and satisfactory recovery was achieved. Based on the above experimental data, the chromatographic separation was finalized by acquity BEH C18 $(100 \times 2.1 \mathrm{~mm}, 1.7 \mu \mathrm{m})$, column using isocratic elution at $235 \mathrm{~nm}$ detection wavelength. The optimized mobile phase consist of buffer $(0.1 \% \mathrm{v} / \mathrm{v}$ triethylamine in water $\mathrm{pH} 6.0$ by glacial acetic acid), acetonitrile in the ratio $(40: 60 \mathrm{v} / \mathrm{v})$, respectively within 4.0 minutes run time, while mobile phase flow rate at $0.4 \mathrm{~mL} / \mathrm{min}, 40{ }^{\circ} \mathrm{C}$ (column oven) temperature with $1 \mu \mathrm{L}$ Injection volume. By using above chromatographic condition and diluent; standard, sample and placebo preparation were prepared and injected into UPLC with developed parameters (Figure 2).

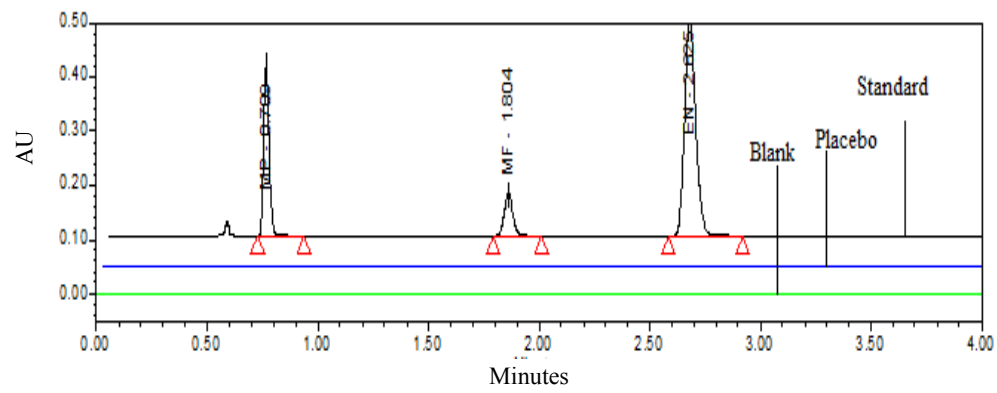

Figure 2. Typical overlay chromatogram of blank and placebo and standard preparation

\section{Analytical method validation}

After satisfactory development of method it was subjected to method validation as per ICH guideline ${ }^{22}$.

\section{System suitability}

System suitability parameters were measured so as to verify the system, method and column performance. The \% RSD (relative standard deviation) of MF, EN and MP peak areas of five replicate injections (standard preparation) were $0.40,0.48$ and 0.70 , respectively. Low values of $\%$ RSD of replicate injections indicate that the system is precise. The tailing factor for MF, EN and MP peaks were 1.3, 1.2 and 1.2. The efficiency of the column, expressed as the number of theroetical plates. Results of theoretical plates for MF, EN and MP peaks are presented in Table 1. 
Table 1. System suitability results (precision, intermediate precision and robustness) for $\mathrm{MP}, \mathrm{MF}$ and EN

\begin{tabular}{lcccccccccc}
\hline \multirow{4}{*}{\multicolumn{1}{c}{ Parameters }} & \multicolumn{3}{c}{$\mathrm{MP}$} & \multicolumn{4}{c}{$\mathrm{MF}$} & \multicolumn{3}{c}{$\mathrm{EN}$} \\
\cline { 2 - 10 } & $\mathrm{N}$ & $\mathrm{T}$ & $\% \mathrm{R}^{*}$ & $\mathrm{~N}$ & $\mathrm{~T}$ & $\% \mathrm{R}^{*}$ & $\mathrm{~N}$ & $\mathrm{~T}$ & $\% \mathrm{R}^{*}$ \\
& $>3000$ & $\leq 2.0$ & $\leq 2.0$ & $>5000$ & $\leq 2.0$ & $\leq 2.0$ & $>7500 \leq 2.0$ & $\leq 2.0$ \\
\hline Precision & 4724 & 1.3 & 0.40 & 10031 & 1.2 & 0.48 & 13994 & 1.2 & 0.70 \\
Intermediate Precision & 4746 & 1.3 & 0.35 & 12204 & 1.2 & 0.32 & 13947 & 1.2 & 0.40 \\
At 0.44 mL/min flow rate & 3724 & 1.3 & 0.39 & 9616 & 1.1 & 0.41 & 10548 & 1.2 & 0.48 \\
At 0.36 mL/min flow rate & 4165 & 1.3 & 0.33 & 10540 & 1.1 & 0.37 & 11511 & 1.2 & 0.39 \\
At 35 ${ }^{\circ} \mathrm{C}$ column & & & & & & & & & \\
Temperature & 4529 & 1.3 & 0.41 & 9996 & 1.2 & 0.23 & 11327 & 1.2 & 0.23 \\
At 45 ${ }^{\circ}$ C column & & & & & & & & & \\
Temperature & 4890 & 1.3 & 0.23 & 9518 & 1.2 & 0.23 & 10283 & 1.2 & 0.26 \\
Mobile phase buffer pH 6.2 & 4347 & 1.3 & 0.38 & 9906 & 1.2 & 0.34 & 13040 & 1.2 & 0.35 \\
$\begin{array}{l}\text { Mobile phase buffer pH 5.8 } \\
\text { MP Comp. [+10\% }\end{array}$ & 4835 & 1.3 & 0.36 & 10084 & 1.2 & 0.29 & 12789 & 1.2 & 0.43 \\
$\begin{array}{l}\text { Acetonitrile] } \\
\text { MP Comp. [-10\% }\end{array}$ & 4190 & 1.3 & 0.28 & 7291 & 1.2 & 0.25 & 10625 & 1.2 & 0.33 \\
Acetonitrile ] & 4636 & 1.3 & 0.19 & 14068 & 1.2 & 0.21 & 16641 & 1.2 & 0.28 \\
\hline
\end{tabular}

${ }^{*}$ Determined on five values. $N$ USP Plate count T USP Tailing factor $R$ \%Relative standard deviation, MP Comp. Mobile phase composition

\section{Specificity-forced degradation studies}

Specificity is the ability of the method to measure the analyte response in the presence of its potential impurities and placebo matrix ${ }^{22}$. Forced degradation studies were performed to demonstrate selectivity and stability indicating capability of the proposed RP-UPLC method. Figure 2 shows that there is no any interferences at the RT (retention time) of MP, MF and EN due to blank, placebo. Overlay chromatograms of blank, placebo and standard are presented in Figure 2.

Force degradation studies of drug product were also performed to evaluate the stability indicating property and specificity of proposed method. The solutions of drug product and placebo were exposed to acid hydrolysis study ( $2 \mathrm{~mL}$ of $1 \mathrm{~N} \mathrm{HCl}$ at RT for $30 \mathrm{~min}$ ), alkali $(0.5 \mathrm{~mL}$ of $0.5 \mathrm{~N} \mathrm{NaOH}$ at RT for $15 \mathrm{~min})$, peroxide oxidation $\left(1 \mathrm{~mL}\right.$ of $10 \% \mathrm{v} / \mathrm{v} \mathrm{H}_{2} \mathrm{O}_{2}$ at RT for $30 \mathrm{~min}$ ), thermally exposed $\left(75^{\circ} \mathrm{C}, 6 \mathrm{~h}\right.$ ) and photolytic exposed (drug product exposed to visible light for $240 \mathrm{~h}$ resulting an overall illustration 1.2 million lux hours and UV light for $250 \mathrm{~h}$ resulting an overall illustration $200 \mathrm{w} \mathrm{h} / \mathrm{m}^{2}$ at $25^{\circ} \mathrm{C}$ ). MF was found sensitive to acid hydrolysis than EN. During acid hydrolysis process, about $18.0 \%$ of MF was degraded and one main degradation peak was observed at $2.127 \mathrm{~min}, 8.6 \%$ of MP was degraded while no degradation was observed in case of EN. MF was found sensitive to base hydrolysis than EN. During base hydrolysis process, about $20.8 \%$ of MF was degraded and one main degradation peak was observed at $2.066 \mathrm{~min}$ while $5.4 \%$ of MP was degraded and no obvious degradation peak was observed, no degradation was observed in case of EN. During photolytic light exposed degradation process, about $37.6 \%$ of MF was degraded and two main degradation peak was observed at $1.288 \mathrm{~min}, 1.495 \mathrm{~min}$, while no degradation was observed in case of EN and MP. No degradation observed for thermally exposed sample $\left(75^{\circ} \mathrm{C}, 6 \mathrm{~h}\right)$ and peroxide oxidation sample $\left(1 \mathrm{~mL}\right.$ of $10 \% \mathrm{v} / \mathrm{v} \mathrm{H}_{2} \mathrm{O}_{2}$ at RT for $\left.30 \mathrm{~min}\right)$. Acid hydrolysis sample, base hydrolysis, peroxide oxidation sample, thermal exposed sample and photolytic light exposed sample 
are presented in Figure 3(a), 3(b), 3(c), 3(d) and 3(e), respectively. Peak due to MP, MF and EN were investigated for spectral purity in the chromatogram of all exposed samples and found spectrally pure. The purity and assay of MP, MF and EN were unaffected by the presence of its degradation products and thus confirms the stability-indicating power of the developed method. Results from forced degradation study are given in Table 2.
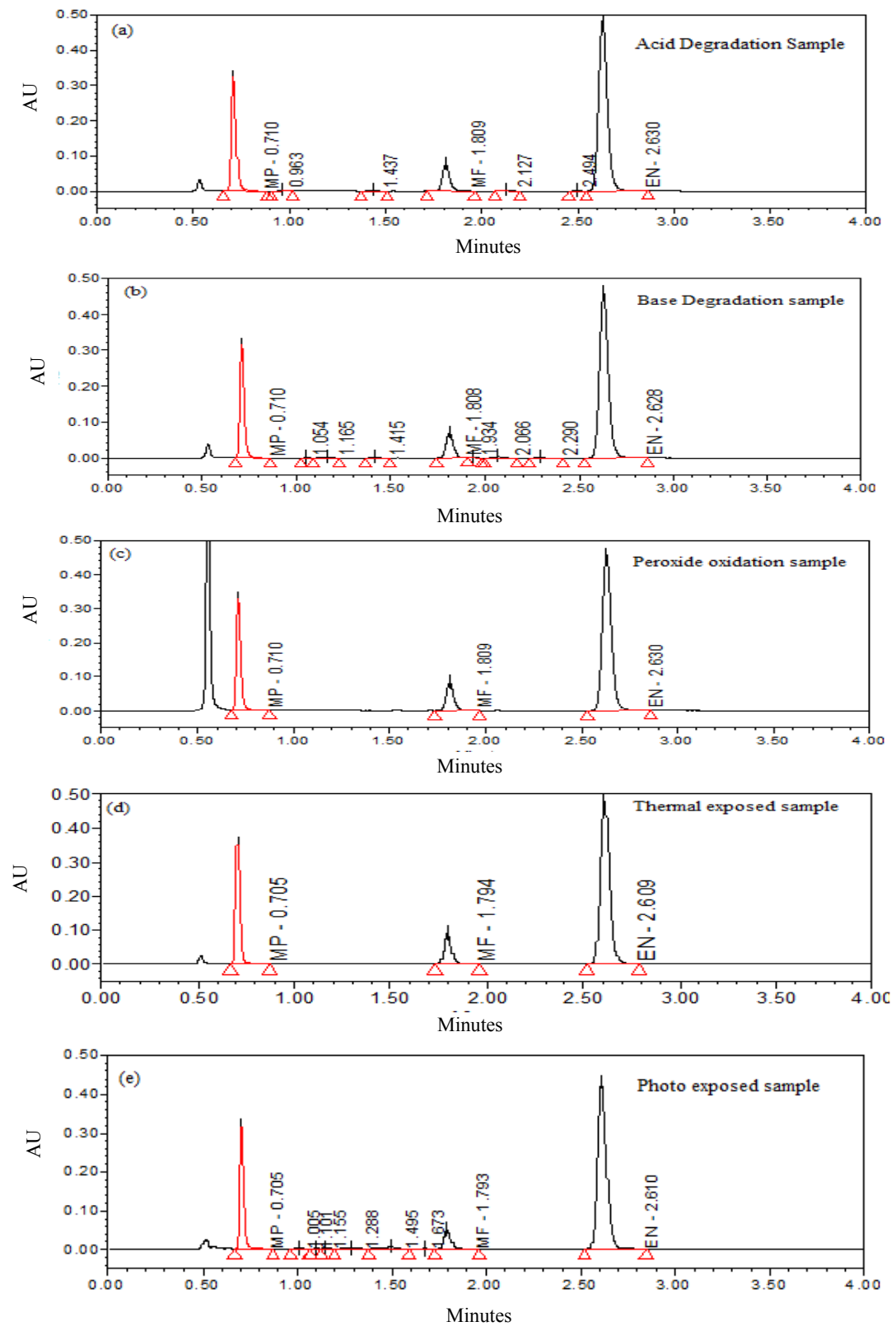

Figure 3. Typical chromatograms of (a) acid degradation sample (b) base degradation sample (c) peroxide oxidation sample (d) thermal exposed sample and (e) photo exposed sample 
Table 2. Results of forced degradation study for MP, MF and EN

\begin{tabular}{|c|c|c|c|c|c|c|c|c|c|}
\hline \multirow[b]{2}{*}{ Stress Conditions } & \multicolumn{3}{|c|}{ MP } & \multicolumn{3}{|c|}{$\mathrm{MF}$} & \multicolumn{3}{|c|}{ EN } \\
\hline & PA & PTH & $\%$ Deg. & PA & PTH & $\%$ Deg. & PA & PTH & $\%$ Deg. \\
\hline $\begin{array}{l}\text { Acidic hydrolysis } \\
\text { (1 N HCl, RT, } 30 \mathrm{~min})\end{array}$ & 0.037 & 1.013 & 8.6 & 0.796 & 1.095 & 18.0 & 0.761 & 1.032 & ND \\
\hline $\begin{array}{l}\text { Alkaline hydrolysis } \\
(0.5 \mathrm{~N} \mathrm{NaOH}, \mathrm{RT}, \\
15 \mathrm{~min})\end{array}$ & 0.032 & 1.008 & 5.4 & 0.633 & 1.056 & 20.8 & 0.716 & 1.030 & ND \\
\hline $\begin{array}{l}\text { Peroxide Oxidation } \\
\left(10 \% \mathrm{H}_{2} \mathrm{O}_{2}, 70{ }^{\circ} \mathrm{C},\right. \\
30 \mathrm{~min})\end{array}$ & 0.039 & 1.008 & ND & 0.478 & 1.054 & ND & 0.740 & 1.031 & ND \\
\hline $\begin{array}{l}\text { Thermal exposed } \\
\left(\text { At } 75^{\circ} \mathrm{C}, 6 \mathrm{~h}\right)\end{array}$ & 0.037 & 1.010 & ND & 0.539 & 1.075 & ND & 0.639 & 1.075 & ND \\
\hline $\begin{array}{l}\text { UV and visible light } \\
\text { exposed }\end{array}$ & 0.054 & 1.022 & ND & 0.756 & 1.254 & 37.6 & 0.728 & 1.065 & ND \\
\hline
\end{tabular}

N.D. No degradation RT room temperature PA purity angle PTH purity threshold

\section{Method precision (Repeatability)}

The precision of assay method was evaluated by carrying out six independent determinations of of MP, MF and EN (100 $\mu \mathrm{g} \mathrm{mL}^{-1}$ of MP, $40 \mu \mathrm{g} \mathrm{mL}^{-1}$ of MF and $400 \mu \mathrm{g} \mathrm{mL}^{-1}$ of EN) cream samples against qualified working standards. The average $\%$ assay $(n=6)$ of MP, MF and EN were $99.8 \%, 100.3 \%$ and $101.6 \%$ respectively with RSD of below $1.0 \%$. Low values of \% RSD, indicates that the method is precise. Results are presented in Table 3.

\section{Intermediate precision (Reproducibility)}

The purpose of this study is to demonstrate the reliability of the test results with variations. The reproducibility was checked by analyzing the samples by different analyst using different chromatographic system and column on different day. Results are presented in Table 3.

\section{Accuracy}

The accuracy was evaluted applying the proposed method to the analysis of the in house mixture of cream excipients with known amount of the drug, to obtain solutions at concentrations of 201.0, 402.0 and $603.0 \mu \mathrm{g} / \mathrm{mL}$ repectively for MP; $20.1,40.2$ and $60.3 \mu \mathrm{g} / \mathrm{mL}$ repectively for MF; 50.6, 101.2 and $151.8 \mu \mathrm{g} / \mathrm{mL}$ repectively for $\mathrm{EN}$. The accuray was assessed from three replicate determination and calculated as the $\mu \mathrm{g} / \mathrm{mL}$ drug recovered from the drug matrix. The means and RSD\% obtained from the recovery study are shown in Table 4 with a range of $99.0-101.7 \%, 99.8-101.1 \%$ and $98.5-101.5 \%$ for MP, MF and EN, respectively, demonstrating that the method is accurate with in the desired range and also there is no interference due to excipients present in placebo cream sample.

\section{Limit of detection (LOD) and quantification (LOQ)}

The LOD and LOQ were determined at a signal-to-noise ratio of 3:1 and 10:1, respectively, by injecting a series of dilute solutions with known concentrations. The limit of detection and limit of quantification values of MP, MF and EN are reported in Table 3. 


\section{Linearity}

Linearity was demonstrated of standard concentration using minimum six calibration levels of test concentration in the range of $2.75-152.7 \mu \mathrm{g} / \mathrm{mL}$ for $\mathrm{MP}, 4.45-60.7 \mu \mathrm{g} / \mathrm{mL}$ for $\mathrm{MF}$ and 9.10-606.6 $\mu \mathrm{g} / \mathrm{mL}$ for EN, which gave us a good confidence on analytical method with respect to linear range. The response was found linear for all MF, EN and MP from LOQ to $150 \%$ of standard concentration and correlation coefficient was also found greater than 0.999. Bias was also found within \pm 0.80 . The result of Correlation coefficients, $y$-intercept of the calibration curve and $\%$ bias at $100 \%$ response for MP, MF and EN are presented in Table 3.

Table 3. Method precision, intermediate precision result, LOD, LOQ evalution and linearity data for MP, MF and EN

\begin{tabular}{lccc}
\hline Parameter & MP & MF & EN \\
\hline $\begin{array}{l}\text { Precision Day-1(n=6) } \\
\text { (\% Assay } \pm \text { SD; \% RSD) }\end{array}$ & $99.8 \pm 0.82 ; 0.82$ & $100.3 \pm 0.64 ; 0.64$ & $101.6 \pm 0.60 ; 0.59$ \\
Intermediate precision & $100.0 \pm 0.95 ; 0.95$ & $99.7 \pm 0.38 ; 0.38$ & $100.9 \pm 0.68 ; 0.67$ \\
Day-2 (n=6) & & & \\
$(\%$ Assay \pm SD; $\%$ RSD) & & & \\
LOD, $\mu \mathrm{g} / \mathrm{mL}$ & 0.837 & 1.351 & 2.755 \\
LOQ, $\mu \mathrm{g} / \mathrm{mL}$ & 2.75 & 4.45 & 9.10 \\
Linearity range, $\mu \mathrm{g} / \mathrm{mL}$ & $2.75-152.7$ & $4.45-60.7$ & $9.10-606.6$ \\
Correlation coefficient & 0.9998 & 0.9998 & 0.9995 \\
Intercept (a) & 910.450 & 465.962 & -11269.364 \\
Slope $(\mathrm{b})$ & 5034.9 & 5561.287 & 3693.053 \\
Bias at $100 \%$ response & 0.177 & 0.208 & -0.774 \\
\hline
\end{tabular}

Table 4. Accuracy results for MP, MF and EN ( $n=3)$

\begin{tabular}{cccc}
\hline Active components & $\begin{array}{c}\text { Amount added, } \\
\mu \mathrm{g} / \mathrm{mL}\end{array}$ & $\begin{array}{c}\text { Amount } \\
\text { recovered, } \mu \mathrm{g} / \mathrm{mL}\end{array}$ & $\begin{array}{c}\text { \% Recovery } \pm \mathrm{SD} ; \% \\
\mathrm{RSD}\end{array}$ \\
\hline \multirow{3}{*}{ Methylparaben } & 201.0 & 204.4 & $101.7 \pm 0.56 ; 0.55$ \\
& 402.0 & 398.1 & $99.0 \pm 0.44 ; 0.45$ \\
& 603.0 & 608.5 & $100.9 \pm 0.36 ; 0.36$ \\
\hline \multirow{3}{*}{ Mometasone furoate } & 20.1 & 20.2 & $100.4 \pm 0.28 ; 0.28$ \\
& 40.2 & 40.1 & $99.8 \pm 0.29 ; 0.29$ \\
& 60.3 & 61.0 & $101.2 \pm 0.44 ; 0.43$ \\
\hline \multirow{3}{*}{ Eberconazole nitrate } & 50.6 & 49.8 & $98.4 \pm 0.42 ; 0.43$ \\
& 101.2 & 101.5 & $100.3 \pm 0.15 ; 0.15$ \\
& 151.8 & 154.1 & $101.5 \pm 0.51 ; 0.51$ \\
\hline
\end{tabular}

\section{Robustness}

The robustness as a measure of method capacity to remain unaffected by small, but deliberate changes in chromatographic conditions was studies by testing influence of small changes in flow rate $(0.4 \pm 0.04 \mathrm{~mL} / \mathrm{min})$, varying in column oven temperature $\left(40 \pm 5{ }^{\circ} \mathrm{C}\right)$, varying mobile phase buffer $\mathrm{pH}(6.0 \pm 0.2)$, varying in mobile phase acetonitrile composition $(60 \pm 10 \%)$. At deliberate varied chromatographic conditions (flow rate, column oven temperature, mobile phase buffer $\mathrm{pH}$, mobile phase acetonitrile composition), \%RSD of MF, EN and MP were calculated from peak area count of five replicate injections. Tailing factor and theoretical plate count remain closer to actual values. Thus, the method was found to be robust with respect to variability in above conditions. The results are presented in Table 1 along with system suitability parameters of precision and intermediate precision study. 


\section{Stability of sample solution}

Stability of sample solution was established by storage it at ambient temperature for $24 \mathrm{~h}$. The assay of MP, MF and EN were analyzed. It was found that \% labeled amount of MP at 0,12 and $24 \mathrm{~h}$ were 99.8, 100.2 and 100.8, respectively; \% labeled amount of MF were 100.3, 99.6 and 99.8, respectively and \% labeled amount of EN were 101.6, 101.7 and 102.1 , respectively.

\section{Filter compatibility}

Sample solution was not showing any significant changes in assay percentage with respect to centrifuged sample. It was found that \% labeled amount of MP at centrifuged sample, $0.22 \mu \mathrm{m}$ PVDF syringe filter and $0.22 \mu \mathrm{m}$ nylon syringe filter were 100.2, 100.2 and 100.5, respectively; MF were 100.5, 100.8 and 99.9, respectively and EN were 101.2, 100.9 and 100.8. In obtained result difference in \%assay was not observed more than \pm 1.0 , which indicates that both syringe filters having a good compatibility with sample solution.

\section{Conclusion}

A rapid isocratic RP-UPLC method was successfully developed for the simultaneous estimation of methylparaben, mometasone furoate and eberconazole nitrate in combined topical pharmaceutical dosage form. The method validation results have proved that the method is selective, precise, accurate, linear, robust, filter compatible and stability indicating. Forced degradation data proved that the method is specific for the analytes and free from the interference of placebo / known impurities / and degradation products. The run time (4.0 min) enables for rapid determination of drug. Moreover, it may be applied for individual and simultaneous determination of methylparaben, mometasone furoate and eberconazole nitrate in the study of content uniformity, tube homogeneity and in vitro release test profiling of mometasone furoate and eberconazole nitrate combined topical pharmaceutical dosage forms, where sample load is higher and high throughput is essential for faster delivery of results. The developed method is stability-indicating and can be used for quantifying methylparaben, mometasone furoate and eberconazole nitrate in topical pharmaceutical dosage forms and their combinations (i.e. $\mathrm{MP}+\mathrm{MF}$; $\mathrm{MP}+\mathrm{EN}, \mathrm{MF}+\mathrm{EN}$ and $\mathrm{MP}+\mathrm{MF}+\mathrm{EN}$ ).

\section{Conflict of interests}

The authors declared that they do not have a direct financial relation with the commercial identity mentioned in this paper that might lead to a conflict of interests for any of the authors.

\section{Acknowledgement}

The authors would like to thank M/s Dr. Reddy's Laboratories Ltd. for supporting this work. The authors' Intellectual Property Management department (IPM) has given this manuscript internal publication number is PUB00225-13

\section{References}

1. Barbanoj M J, Antonijoan R, Garcia-Gea C, Puntes M, Gich I and Jane F, Methods Find Exp Clin Pharm., 2005, 27(4), 227-234; DOI:10.1358/mf.2005.27.4.893581

2. Krishna M V, Dash R N, Reddy B J, Sandeep P, Venugopal P and Madhavi G, $J$ Soudi Chem Society, 2012; DOI:10.1016/J.JSCS.2012.12.001

3. Krishna M V, Dash R N, Reddy B J, Sandeep P, Venugopal P and Madhavi G, Acta Chromatographica, 2013, 25(3), 503-518; DOI:10.1556/ACHROM.25.2013.3.7 
4. Beesley $\mathrm{T}$ E, Redman S, Lee $\mathrm{J} T$ and Gal J, Astec., 2006, 1-13; http://www.sigmaaldrich.com/etc/medialib/docs/Supelco/General_Information/astec 71.Par.0001.File.tmp/astec_71.pdf

5. Srinivasarao K, Gorule V, $\overline{\mathrm{C}} \mathrm{V}$ V R and Krishna V, J Anal Bioanal Technol., 2012, 3, 1-4; DOI:10.4172/2155-9872.1000153

6. Shaikh S, Muneera M S, Thusleem O A, Tahir M and Kondaguli A V, J Chromatogr Sci., 2009, 47(2), 178-183; DOI:10.1093/chromsci/47.2.178

7. Shabir G A, J Liquid Chromatogr Related Technol., 2010, 33(20), 1802-1813; DOI:10.1080/10826076.2010.532702

8. Kuang L K and You-Zung H, J Chromatogr A.,1997, 768(2), 334-341; DOI:10.1016/S0021-9673(97)00040-X

9. Boonleang J and Tanthana C, Songklanakarin J Sci Technol., 2010, 32(4), 379-385.

10. Wang Z, Zhang H, Liu O and Donovan B, The $5^{\text {th }}$ International Conference on SFC, 2011.

11. Teng X W, Foe K, Brown K F, Cutler D J and Davies N M, J Pharm Biomed Anal., 2001, 26(2), 313-319; DOI:10.1016/S0731-7085(01)00408-3

12. Zhu J and Coscolluella C, J Chromatogr B: Biomed Sci., 2000, 741(1), 55-65; DOI:10.1016/S0378-4347(99)00538-1

13. Donovan J C and Dekoven J G, Dermatitis, 2006, 17, 147-151.

14. Korting H C, Maslen K, Gross G and Willers C, J Dtsch Dermatol Gesellschaft, 2005, 3, 348-353.

15. Shaikh K A and Patil A T, J Trace Anal Food Drugs, 2013, 1, 14-21. DOI:10.7726/jtafd.2013.1002.

16. USP 29 NF 24, United States Pharmacopoeia, U. S Pharmacopeial Convention, Inc., Rockville, MD, 2006.

17. Sahasranaman S, Tang Y, Biniasz D, Hochhaus G A, J Chromatogr B Anal Technol Biomed Life Sci., 2005, 819, 175-179.

18. Chen G, Pramanik B N, Liu Y H and Mirza U A, J Mass Spectrometry, 2007, 42(3), 279-287; DOI:10.1002/jms.1184

19. Ekiert R J, Krzek J and Talik P, Talanta, 2010, 82(4), 1090-1100; DOI:10.1016/j.talanta.2010.06.056

20. Ayad M M, EL-Henawee M M, Abdellatef H E and EL Sayed H M, Cairo Bull., 2005, 43(3).

21. ICH Q1A (R2), Stability Testing of New Drug Substances and Products, Geneva, 2000.

22. ICH Q2 (R1), Validation of Analytical Procedures: Text and Methodology, 2005. 